\title{
Intraoperative costs of video-assisted thoracoscopic lobectomy can be dramatically reduced without compromising outcomes
}

\author{
Michael T. Richardson, BA, ${ }^{\mathrm{a}}$ Leah M. Backhus, MD, MPH, ${ }^{\mathrm{b}}$ Mark F. Berry, MD, ${ }^{\mathrm{b}}$ Daniel G. Vail, BA, ${ }^{\mathrm{a}}$ \\ Kelsey C. Ayers, BA, ${ }^{\mathrm{b}}$ Jalen A. Benson, BA, ${ }^{\mathrm{b}}$ Prasha Bhandari, MPH, ${ }^{\mathrm{b}}$ Mehran Teymourtash, MBA, ${ }^{\mathrm{c}}$ and \\ Joseph B. Shrager, MD ${ }^{\mathrm{b}}$
}

\section{ABSTRACT}

Objective: To determine whether surgeon selection of instrumentation and other supplies during video-assisted thoracoscopic lobectomy (VATSL) can safely reduce intraoperative costs.

Methods: In this retrospective, cost-focused review of all video-assisted thoracoscopic surgery anatomic lung resections performed by 2 surgeons at a single institution between 2010 and 2014, we compared VATSL hospital costs and perioperative outcomes between the surgeons, as well as costs of VATSL compared with thoracotomy lobectomy (THORL).

Results: A total of 100 VATSLs were performed by surgeon A, and 70 were performed by surgeon B. The preoperative risk factors did not differ significantly between the 2 groups of surgeries. Mean VATSL total hospital costs per case were $24 \%$ percent greater for surgeon A compared with surgeon B $(P=.0026)$. Intraoperative supply costs accounted for most of this cost difference and were $85 \%$ greater for surgeon A compared with surgeon $\mathrm{B}(P<.0001)$. The use of nonstapler supplies, including energy devices, sealants, and disposables, drove intraoperative costs, accounting for $55 \%$ of the difference in intraoperative supply costs between the surgeons. Operative time was $25 \%$ longer for surgeon A compared with surgeon $\mathrm{B}(P<.0001)$, but this accounted for only $11 \%$ of the difference in total cost. Surgeon A's overall VATSL costs per case were similar to those of THORLs $(\mathrm{n}=100)$ performed over the same time period, whereas surgeon B's VATSL costs per case were $24 \%$ less than those of THORLs. On adjusted analysis, there was no difference in VATSL perioperative outcomes between the 2 surgeons.

Conclusions: The costs of VATSL differ substantially among surgeons and are heavily influenced by the use of disposable equipment/devices. Surgeons can substantially reduce the costs of VATSL to far lower than those of THORL without compromising surgical outcomes through prudent use of costly instruments and technologies. (J Thorac Cardiovasc Surg 2018;155:1267-77)

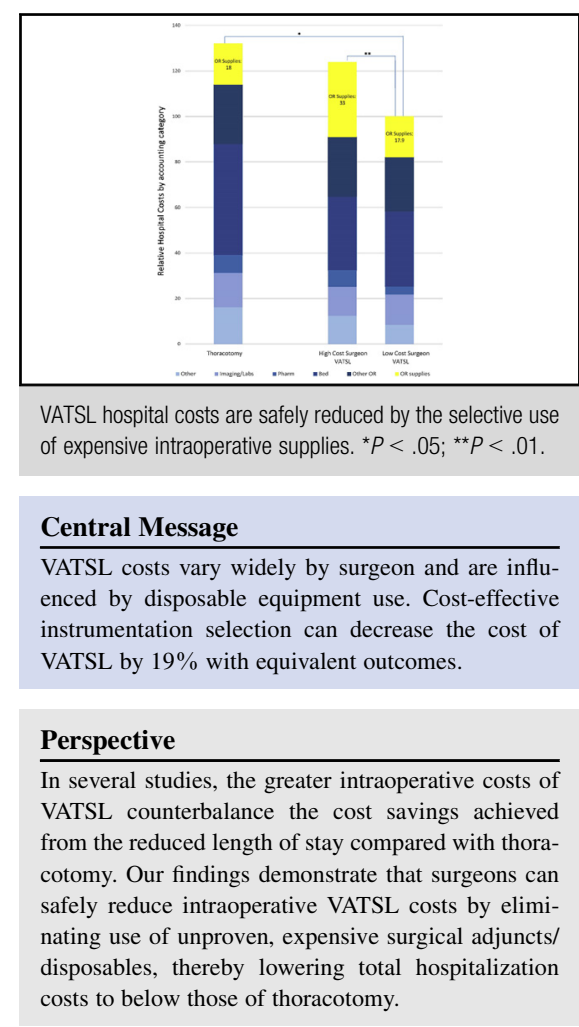

See Editorial Commentary page 1278.

See Editorial page 1211.

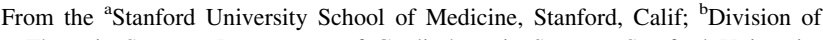
Thoracic Surgery, Department of Cardiothoracic Surgery, Stanford University School of Medicine, Stanford, Calif; and ${ }^{\mathrm{c}}$ Stanford Health Care, Stanford, Calif. Funding for this work was provided by the Stanford Medical Scholars Research Program.

Read at the 97th Annual Meeting of The American Association for Thoracic Surgery, Boston, Massachusetts, April 29-May 3, 2017.

Received for publication April 17, 2017; revisions received Aug 11, 2017; accepted for publication Aug 25, 2017; available ahead of print Dec 7, 2017.

Address for reprints: Joseph B. Shrager, MD, 300 Pasteur Drive, MC 5407, Stanford,

CA 94305 (E-mail: shrager@stanford.edu).

$0022-5223 / \$ 36.00$

Copyright (c) 2017 by The American Association for Thoracic Surgery

https://doi.org/10.1016/j.jtcvs.2017.08.146
}

Pulmonary lobectomy performed via video-assisted thoracoscopy lobectomy (VATSL) has been consistently documented to be associated with shorter length of hospital

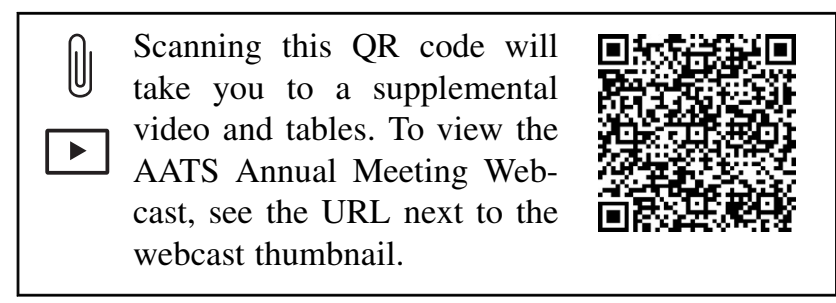




\section{Abbreviations and Acronyms \\ $\mathrm{OR}=$ operating room \\ STS $=$ Society of Thoracic Surgeons \\ THORL $=$ thoracotomy lobectomy \\ VATSL $=$ video-assisted thoracoscopic lobectomy}

stay $^{1-6}$ and slightly lower complication rates compared with thoracotomy lobectomy (THORL). ${ }^{1-3,6-10}$ Economic analyses have determined that postdischarge costs are lower after VATSL than after THORL, ${ }^{11,12}$ but have been inconsistent in finding an in-hospital cost benefit for VATSL. ${ }^{11-15}$ Several studies have suggested that the greater intraoperative costs of VATSL compared with THORL is why overall hospital costs have not been lower for VATSL. ${ }^{14,16,17}$

Given the strong shift toward value-based health care, we sought to determine whether the higher intraoperative costs of VATSL compared with THORL ${ }^{14,16,17}$ can be favorably impacted by surgeons' intraoperative choices and, if so, whether these more cost-effective choices can be made without adversely affecting outcomes. We further hypothesized that a cost-effective surgeon could perform VATSL with equal or reduced intraoperative and total in-hospital costs compared with THORL. We addressed these questions by studying overall hospital and intraoperative costs of VATSLs and THORLs performed by 2 surgeons, one who tended to consider costs in his choice of devices/instruments and the other who was less focused on cost savings and tended to be an earlier adopter of novel devices.

\section{METHODS}

\section{Study Population and Clinical Data Collection}

We retrospectively reviewed prospectively collected data on all patients who underwent VATSL, video-assisted thoracoscopy segmentectomy, or video-assisted thoracoscopy bilobectomy by 2 surgeons at Stanford University Hospital in fiscal years 2010 to 2014 (September 2009 to August 2013). We also collected data for all 100 THORLs performed by these 2 surgeons during the same period. Sleeve lobectomies were excluded. Approval for this study was obtained from the Institutional Review Board of Stanford University, which exempted the study from the typical requirement for informed consent given the nature of the study. Although our analysis is performed from a hospital cost perspective, in a setting of limited societal resources, the hospital perspective clearly has implications for society as a whole.

We used the Society of Thoracic Surgeons (STS) General Thoracic Database entries for our patients (with additional custom fields that we added) to collect demographic information and data on staging (American Joint Committee on Cancer Staging Manual, 7th edition), preoperative comorbidities, pulmonary function tests, operative variables, and postoperative outcomes. The only comorbidity defined differently from the STS database definition was our use of creatinine concentration $\geq 1.2 \mathrm{mg} / \mathrm{dL}$ as a comorbidity. When required data were unavailable in the STS database fields, we retrospectively queried the electronic medical record.

VATSLs that were converted to THORLs were included in the VATSL group (intention-to-treat analysis). One patient (out of 270) was excluded in the outcomes analysis because of unavailable data. VATSLs were performed using a 3-incision or 3-port technique, except in rare instances where a fourth was added. Postoperative management was provided at the discretion of the individual surgeon.

Operating room (OR) time was defined as time from anesthesia induction to extubation and thus included time for bronchoscopy, positioning, and mediastinoscopy when performed. The use of glues, gels, and adjuncts, such as the LigaSure device (Medtronic, Minneapolis, Minn) or a harmonic scalpel was recorded, as were intraoperative blood loss and blood transfusion. When blood loss was recorded as "minimal," we used a value of $25 \mathrm{~mL}$. Intraoperative complications were defined as surgeries requiring blood transfusions and those requiring conversion to thoracotomy due to bleeding.

Major postoperative complications collected included acute respiratory distress syndrome, atelectasis requiring bronchoscopy, bronchopleural fistula, chylothorax requiring intervention, delirium, empyema, new central neurologic event, other events requiring use of the operating room (OR) with general anesthesia, other neurologic events, pneumonia, respiratory failure requiring reintubation, unexpected admission to the intensive care unit, and unexpected return to the OR. The duration of chest tube insertion and air leak, as well as the incidence of prolonged air leak ( $>5$ days), were recorded as well.

\section{Financial Data Collection}

In-hospital costs for the index hospitalization during which surgery (VATSL or THORL) was performed were collected by Stanford Health Care Finance Department personnel. The hospital agreed to provide the research team with relative (but not absolute) direct technical cost data for each patient and surgeon. The data were separated into intraoperative and postoperative costs and then into several different categories within each of these subdivisions. Intraoperative costs were broken down into OR supplies and other OR costs (with the latter essentially determined by OR time). Postoperative costs were broken down into bed costs, pharmacy costs, supply costs, imaging/laboratory test costs, and other costs. Costs were compared between the 2 surgeons, and the data were analyzed to identify the main drivers of any cost differences identified.

Stanford Hospital uses a complicated internal method of coding for specific devices used in the OR. Using this coding system plus the surgeons' operative reports, we were able to identify nearly all of the specific devices used in the various procedures; however, approximately $5 \%$ of device codes could not be successfully affiliated with a specific device, which was an insufficient percentage to alter our results in any substantial way.

\section{Data Analysis}

Differences in all outcomes between surgeon A and surgeon B were first assessed in bivariate analyses, without adjusting for patient demographic data or tumor stage. Differences in patient and tumor characteristics were also assessed between surgeon A's VATSL patients and surgeon B's VATSL patients, as well as between all VATSL patients and all THORL patients, to determine whether the surgeons were operating on a similar patient population and to explore how the VATSL and THORL patients differed. Finally, differences in all outcomes between the 2 surgeons were analyzed in multivariable regression models, adjusting for differences in the 2 surgeons' patient populations. All clinically relevant patient characteristics (including stage) that differed between the 2 surgeons at a threshold of $P<.20$ were included as covariates in the adjusted analyses. A linear regression model was used for continuous data, and a logistic regression was used for binary variables.

Separate statistical analyses of cost data were performed by the Stanford Health Care Finance Department, with close guidance from the clinical research team. This was necessary because the clinical team was blinded to the crude financial data.

A $P$ value $<.05$ was considered to indicate statistical significance. All analyses were conducted in Excel (Microsoft, Redmond, Wash), GraphPad 
TABLE 1. VATSL patient demographics and preoperative risk factors

\begin{tabular}{lccc}
\hline \multicolumn{1}{c}{ Variable } & Surgeon A & Surgeon B & P value \\
\hline Number of patients & 99 & 70 & $64(12.76)$ \\
Age, y, mean (SD) & $66.01(12.99)$ & $50(71)$ & .49 \\
Female sex, $\mathrm{n}(\%)$ & $58(58)$ & $93.97(25.50)$ & .087 \\
$\%$ of predicted FEV ${ }_{1}$, mean (SD) & $91.24(20.64)$ & $28(40)$ & .45 \\
Major comorbidities, $\mathrm{n}(\%)$ & $49(49)$ & $0(0)$ & .22 \\
Peripheral vascular disease, $\mathrm{n}(\%)$ & $2(2)$ & $2(3)$ & .23 \\
Cerebrovascular history, $\mathrm{n}(\%)$ & $2(2)$ & $11(16)$ & .73 \\
Congestive heart failure, $\mathrm{n}(\%)$ & $4(4)$ & $3(4)$ & .68 \\
Chronic obstructive pulmonary disease, $\mathrm{n}(\%)$ & $18(18)$ & $4(6)$ \\
Coronary artery disease, $\mathrm{n}(\%)$ & $10(10)$ & $12(17)$ \\
\hline Diabetes, $\mathrm{n}(\%)$ & $18(18)$ & .68 \\
Creatinine $\geq 1.2 \mathrm{mg} / \mathrm{dL}, \mathrm{n}(\%)$ & $21(21)$ & .16 \\
\hline
\end{tabular}

$S D$, Standard deviation; $F E V_{l}$, forced expiratory volume in 1 second.

Online Calculator (GraphPad Software, La Jolla, Calif), or Stata software (StataCorp, College Station, Tex).

\section{RESULTS}

A total of 170 VATSLs and 100 THORLs were analyzed; demographic and outcomes data were available for 169 of the 170 VATSL patients. The less cost-conscious surgeon was designated "surgeon A," and the more costconscious surgeon was designated "surgeon B." Surgeon A performed 100 VATSL resections, and surgeon B performed 70 . Overall annual operative volume (all operations) was similar in the 2 surgeons. Surgeon A had 2 years of attending surgical experience before the start of the study, compared with 12 years for surgeon B.

\section{Patient and Tumor Characteristics}

Demographic data, comorbidities, and pulmonary function test results of VATSL patients treated by the 2 surgeons are presented in Table 1. Among demographics and comorbidities, only the incidence of diabetes differed significantly between the patients of the 2 surgeons $(P=.018)$. Because along with diabetes incidence, the difference in the incidence of coronary artery disease $(P=.16)$ was below $P=.20$, both of these factors were included in our regression model, along with tumor stage, when analyzing patient outcomes.

Type and location of disease, disease stage, and type of procedure performed for VATSL operations are shown in Table 2. None of these differed significantly between the surgeons. Nineteen patients of surgeon A had a disease other than primary lung cancer, compared with 15 patient of surgeon B. All other patients underwent VATSL for primary lung cancer. Although disease stage did not differ significantly between the 2 surgeons $(P=.13)$, because the univariate $P$ value was $<.20$, this factor was also included in our regression model.

Comparisons of preoperative VATSL and THORL patient data are presented in Tables E1 and E2, showing some differences between the 2 populations. The THORL patients had higher tumor stage, as might be expected. Compared with VATSL patients, these patients were also more likely to be younger, to be male, to have fewer comorbidities, and to undergo lobectomy (vs segmentectomy).

TABLE 2. VATSL tumor characteristics and procedures performed

\begin{tabular}{|c|c|c|c|}
\hline Characteristic & $\begin{array}{l}\text { Surgeon } \\
\text { A, n ( } \%)\end{array}$ & $\begin{array}{l}\text { Surgeon } \\
\text { B, n }(\%)\end{array}$ & $\begin{array}{c}P \text { value } \\
\text { for category }\end{array}$ \\
\hline Number of patients & 99 & 70 & \\
\hline Disease category & & & .72 \\
\hline Primary: upper lobe & $40(40)$ & $32(46)$ & \\
\hline Primary: middle lobe & $5(5)$ & $4(6)$ & \\
\hline Primary: lower lobe & $35(35)$ & $19(27)$ & \\
\hline Metastasis & $13(13)$ & $8(11)$ & \\
\hline Other & $6(6)$ & $7(10)$ & \\
\hline Tumor stage* & & & .13 \\
\hline Stage IA & $51(64)$ & $42(76)$ & \\
\hline Stage IB & $14(18)$ & $10(18)$ & \\
\hline Stage IIA & $8(10)$ & $0(0)$ & \\
\hline Stage IIB & $4(5)$ & $1(2)$ & \\
\hline Stage IIIA & $3(4)$ & $2(4)$ & \\
\hline Lobe involvement & & & .87 \\
\hline Upper lobe & $47(47)$ & $36(51)$ & \\
\hline Middle lobe & $7(7)$ & $5(7)$ & \\
\hline Lower lobe & $45(45)$ & $29(41)$ & \\
\hline Type of procedure & & & .99 \\
\hline Lobectomy & $82(82)$ & $58(83)$ & \\
\hline Segmentectomy & $17(17)$ & $12(17)$ & \\
\hline
\end{tabular}

*For tumor stage, the denominator is the number of patients with primary lung cancer. 


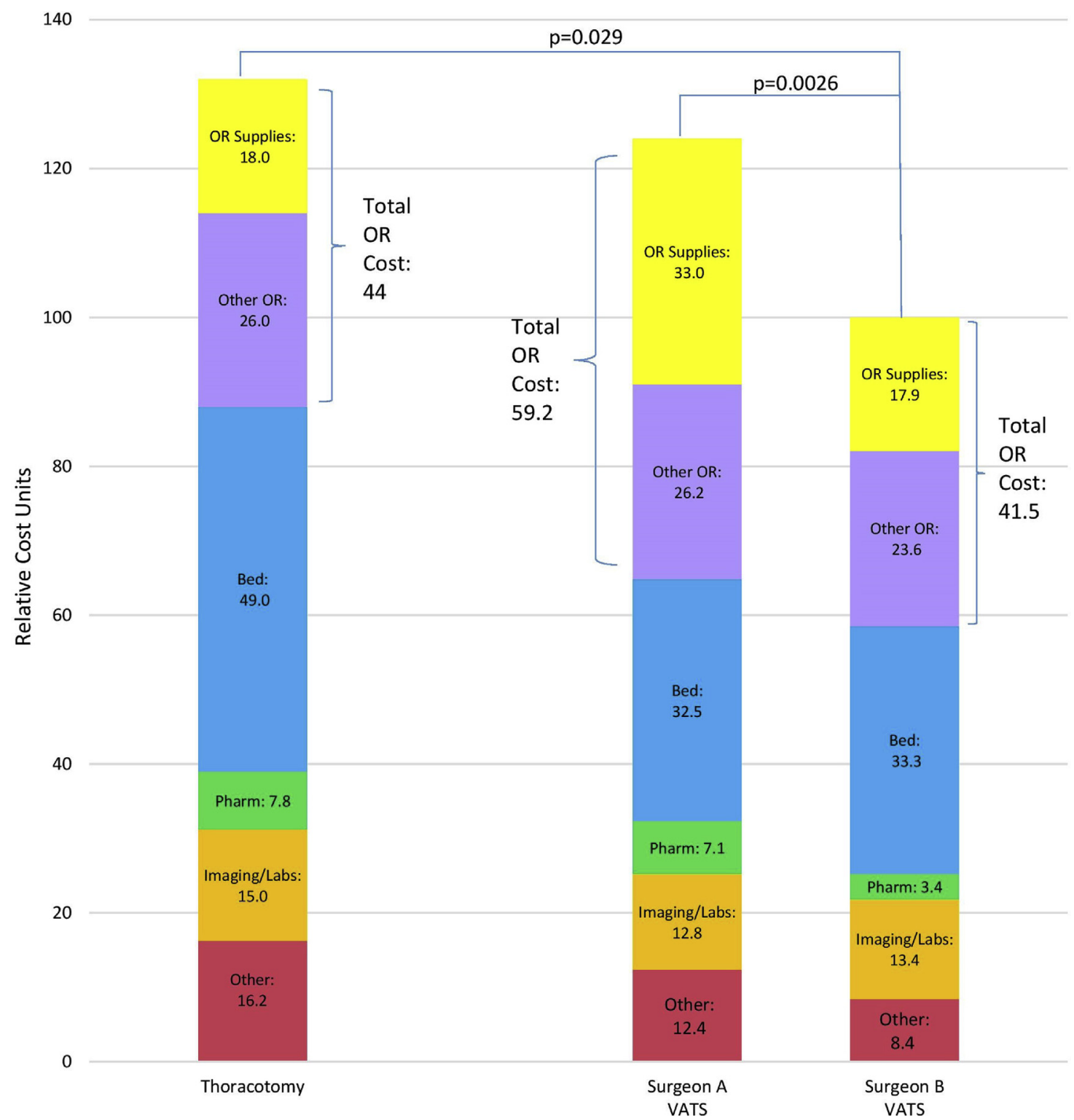

FIGURE 1. Relative hospital costs associated with VATSL by 2 surgeons, according to accounting category, compared with all open thoracotomies. ${ }^{\#}$ The low-cost surgeon/surgeon B's total costs were set at a value of 100. The "other OR" category consists essentially of the costs associated with OR time. OR, Operating room; VATS, video-assisted thoracoscopic.

\section{Cost Data}

Because raw financial data were not provided to the research team, only relative values are presented herein. Figure 1 shows mean overall hospital costs per case associated with VATSL and THORL for the 2 surgeons. Surgeon B's overall hospital costs for VATSL was set at a relative value of 100 for comparison purposes. The mean hospital costs per VATSL case were $24 \%$ higher $(P=.0026)$ for surgeon A than for surgeon B (124 relative units). Furthermore, the mean hospital costs per case were $32 \%$ higher for THORL compared with VATSL for surgeon B (132 relative units; $P=.029)$, but not significantly different than those for VATSL for surgeon A $(P=.55)$.

When comparing VATSLs performed by the 2 surgeons, intraoperative costs were the primary driver of the differences between the surgeons' total hospital costs. Intraoperative costs accounted for $41.5 \%$ of surgeon A's total costs (41.5 relative units) and $47.8 \%$ of surgeon B's total costs (59.2 relative units; $P<.0001)$.

We further divided intraoperative costs into "OR supplies" and "other OR" (Figure 1), the latter comprising the costs of personnel and of the OR time itself. Although 


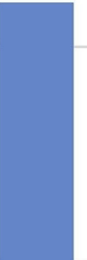

40

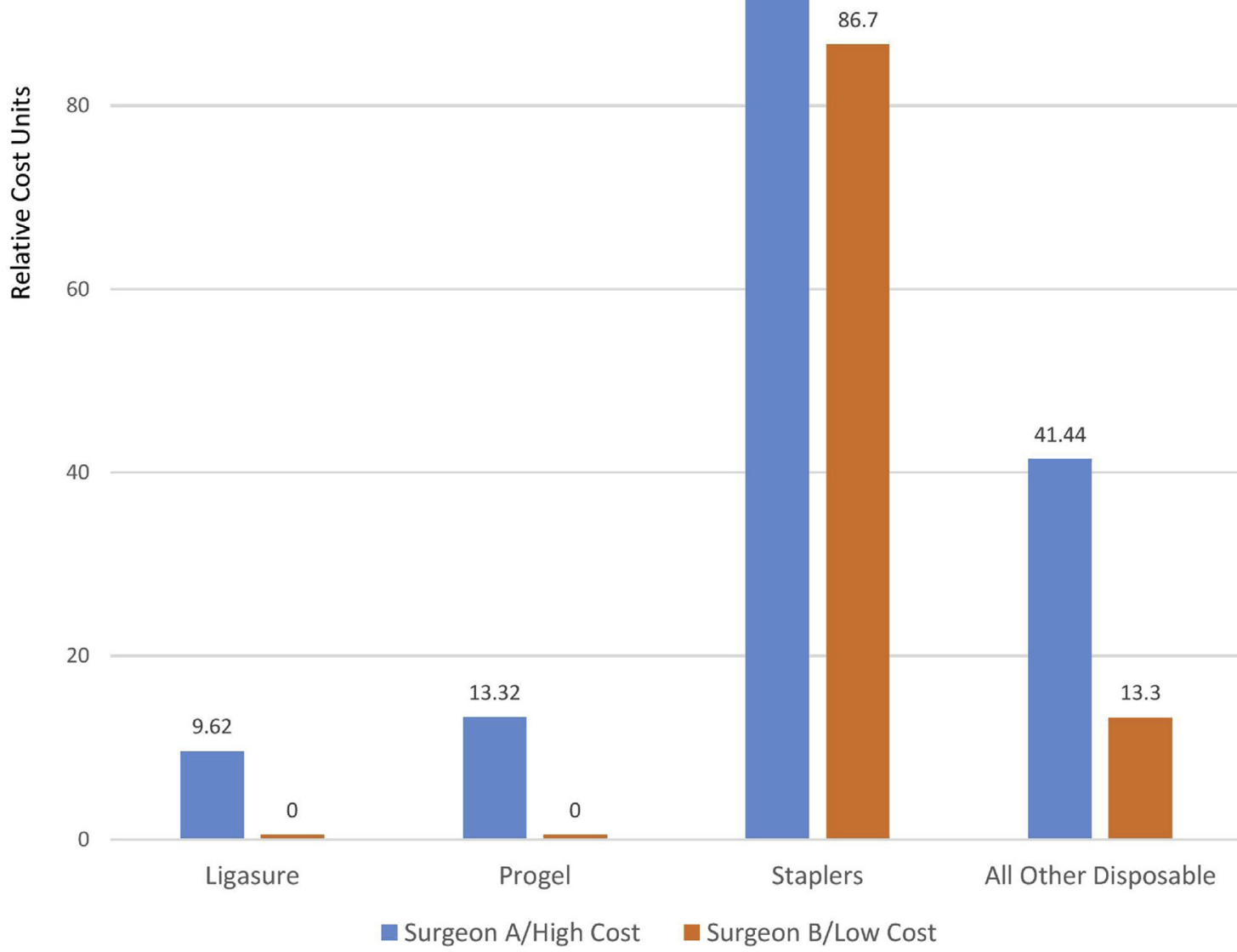

FIGURE 2. Components of intraoperative supply costs. The "all other" category includes all disposables besides those shown in the other bars in this figure.

surgeon A's VATSL cases took 25\% longer than surgeon B's $(P<.0001)$, the costs of OR time accounted for only $11 \%$ of the difference in total costs between the 2 surgeons.

The most significant difference between the surgeons in terms of intraoperative costs was the costs of OR supplies. The cost of OR supplies was $85 \%$ greater for surgeon A compared with surgeon B (33.0 vs 17.9 relative units; $P<.0001$ ), accounting for $63 \%$ of the difference in overall hospital costs between the 2 surgeons.

Figure 2 shows the intraoperative supply items that contributed most to the intraoperative costs for each surgeon. Stapling devices were the greatest single component of intraoperative costs for both surgeons, and absolute stapler costs were $48 \%$ greater for surgeon A compared with surgeon B. However, the largest driver of the intersurgeon difference in intraoperative cost was the selection/use of nonstapler supplies, including energy devices (eg, LigaSure), staple line sealants (eg, Progel), and disposables such as commercial ports and endo scissors. When combined, the costs of these discretionary adjuncts accounted for $54 \%$ of the difference in intraoperative supply cost between surgeons. 
TABLE 3. Intraoperative data and outcomes

\begin{tabular}{|c|c|c|c|c|}
\hline Outcome & Surgeon A & Surgeon B & $P$ value, unadjusted & $P$ value, adjusted $*$ \\
\hline Number of patients & 99 & 70 & & \\
\hline OR time, $\mathrm{h}$, mean (SD) $\dagger, \ddagger$ & $4.91(1.88)$ & $3.81(1.57)$ & $<.01 \S$ & $.02 \S$ \\
\hline Blood loss, mL, mean (SD) $\ddagger$ & $110.303(111.011)$ & $113.643(134.649)$ & .50 & .63 \\
\hline Blood transfusions, $\mathrm{n}(\%)$ & $3(3 \%)$ & $2(3)$ & .95 & .99 \\
\hline Intraoperative complications, $\mathrm{n}(\%)$ & $3(3 \%)$ & $5(7)$ & .23 & .19 \\
\hline
\end{tabular}

$O R$, Operating room; $S D$, standard deviation. *Adjusted $P$ values were calculated using a linear regression model for OR time and blood loss and a logistic regression model for blood transfusions and intraoperative complications, accounting for intersurgeon differences in patient stage, diabetes, and coronary artery disease. Intraoperative complications were defined as conversions for bleeding and blood transfusions. †OR time included bronchoscopy, mediastinoscopy when performed, positioning, lung resection, and closure, and is given in total time. $\ddagger$ Data were not normally distributed, and a Mann-Whitney test was run to compare data. $\S P \leq .05$.

In contrast to VATSLs, in THORLs the main driver of overall hospital costs was the embedded cost of each day in the hospital (Figure 1). These "bed" costs accounted for $37.1 \%$ of total THORL-related hospital costs (49 relative units), compared with $26.2 \%$ of the VATSL costs for surgeon A (32.5 relative units) and 33.3\% of the VATSL costs for surgeon B (33.3 relative units). The impact of these bed costs stems directly from the higher mean length of stay for THORL compared with VATSL (6.1 days vs 4.4 days; $P=.0003)$. The extra bed costs represented $49 \%$ of the difference in overall hospital costs between THORL and VATSL and largely explains the increased costs of open thoracotomy compared with the low-cost surgeon.

Finally, for surgeon B, the overall costs of VATSLs were $24 \%$ lower than those for all THORLs $(P=.020)$, whereas for surgeon A, the overall costs of VATSLs were not significantly different than those for all THORLs $(P=.55)$.

\section{Operative Details and Patient Outcomes}

Surgeon B's ability to reduce the costs of VATSL by limiting his intraoperative supply costs would not be something to aspire to if it was at the expense of more intraoperative complications or poorer patient outcomes. Thus, we examined patient outcomes between the 2 surgeons.

Operative data and intraoperative outcomes are shown in Table 3. The distribution of procedures was similar for the 2 surgeons, as were the locations and categories of disease. Eleven cases $(6 \%)$ were converted to thoracotomy ( 6 for surgeon A, 5 for surgeon $\mathrm{B} ; P=.76$ ). Mean intraoperative blood loss was $108 \mathrm{~mL}$ for surgeon $\mathrm{A}$ and $113 \mathrm{~mL}$ for surgeon $\mathrm{B}(P=.78)$. Three patients of surgeon A required blood transfusion, compared with 1 patient of surgeon $\mathrm{B}(P=.95)$. There remained no significant differences in any of these intraoperative outcomes when the regression model accounting for differences in comorbidities and stage between the surgeons' patients was applied.

Postoperative patient outcomes are shown in Table 4. There were no significant differences on univariate analysis for any outcomes evaluated, including length of stay, duration of chest tube insertion, prolonged chest tube insertion, prolonged air leak, or total major complications. After applying our regression model, no outcomes were statistically significantly different between the 2 surgeons.

\section{DISCUSSION}

This study demonstrates first that VATSL costs can vary dramatically between surgeons. Even though the 2 surgeons operated on a similar patient population and had virtually identical patient outcomes, the overall in-hospital costs of VATSL were $24 \%$ greater for surgeon A (the higher-cost surgeon) compared with surgeon B (the lower-cost surgeon). We have shown that these cost differences are accounted for primarily by the differences in the costs of OR supplies used, particularly energy devices (eg, LigaSure), staple line sealants (eg, Progel), and disposables, such as plastic ports and instruments. Our data show that these costs can be safely reduced when surgeons make conscious, cost-effective instrumentation and supply choices (Video 1).

Our data also show that when cost-conscious intraoperative decisions are made by surgeons, total in-hospital costs of VATSL can be safely reduced to well below the inhospital costs of THORL. Because studies have been inconsistent in demonstrating total in-hospital cost benefits for VATSL over THORL, ${ }^{11-15}$ our work provides an explanation for the often higher intraoperative costs associated with VATSL. ${ }^{14,16,17}$ Furthermore, given the lower postdischarge costs after VATSL than after THORL, ${ }^{11,12}$ our findings suggest that overall costs of the entire episode of care surrounding VATSL will be substantially lower than those of THORL if surgeons make cost-conscious intraoperative decisions.

Our 2 study surgeons took substantially different approaches to the performance of VATSL. Surgeon A (the higher-cost surgeon) routinely used disposable, commercial introducers and tended to be an early adopter of expensive surgical devices (eg, energy devices) and adjuncts (eg, sealants). Surgeon B (the lower-cost surgeon) consciously avoided the use of expensive adjuncts that he felt did not have (or at least had not been clearly proven to have) substantial clinical benefits. He used reusable ports and instruments almost exclusively. He never used energy devices 
TABLE 4. Postoperative outcomes

\begin{tabular}{|c|c|c|c|c|}
\hline Outcome & Surgeon A & Surgeon B & $P$ value, unadjusted & $P$ value, adjusted $*$ \\
\hline Number of patients & 99 & 70 & & \\
\hline LOS from surgery to discharge, $d$, mean (SD) & $4.35(2.07)$ & $4.31(2.44)$ & .91 & .78 \\
\hline Duration of chest tube, $d$, mean (SD) & $3.05(2.44)$ & $3.4(2.90)$ & .40 & .68 \\
\hline Duration of air leak, d, mean (SD) & $1.61(2.22)$ & $1.53(2.82)$ & .84 & .66 \\
\hline Prolonged air leak $(>5 \mathrm{~d}), \mathrm{n}(\%)$ & $10(10)$ & $3(4)$ & .18 & .065 \\
\hline Acute respiratory distress syndrome, $\mathrm{n}(\%)$ & $2(2)$ & $1(1)$ & .78 & .65 \\
\hline Atelectasis requiring bronchoscopy, $\mathrm{n}(\%)$ & $3(3)$ & $0(0)$ & .14 & .18 \\
\hline Chylothorax requiring medical intervention, $\mathrm{n}(\%)$ & $0(0)$ & $1(1)$ & .24 & .31 \\
\hline Delirium, $\mathrm{n}(\%)$ & $2(2)$ & $5(7)$ & .12 & .10 \\
\hline Other events requiring OR with general anesthesia, $\mathrm{n}(\%)$ & $0(0)$ & $1(1)$ & .24 & .31 \\
\hline Pneumonia, n (\%) & $1(1)$ & $2(3)$ & .39 & .38 \\
\hline Respiratory failure requiring intubation, $\mathrm{n}(\%)$ & $0(0)$ & $1(1)$ & .24 & .31 \\
\hline Unexpected admission to ICU, $\mathrm{n}(\%)$ & $2(2)$ & $2(3)$ & .73 & .40 \\
\hline Unexpected return to OR, $\mathrm{n}(\%)$ & $1(1)$ & $2(3)$ & .37 & .34 \\
\hline Patients with adverse outcomes, $\mathrm{n}(\%)$ & $6(6)$ & $7(10)$ & .35 & .22 \\
\hline Total number of adverse outcomes & 11 & 11 & .58 & .24 \\
\hline
\end{tabular}

$L O S$, Length of stay; $S D$, standard deviation; $O R$, operating room; $I C U$, intensive care unit. There were no $P$ values of $\leq .05 .{ }^{*}$ Adjusted coefficients and $P$ values were calculated using a linear regression model accounting for intersurgeon differences in patient stage, diabetes, and coronary artery disease for total number of adverse outcomes, air leak duration, LOS from surgery to discharge, and chest tube duration, and a logistic regression model for all other variables. Bronchopleural fistula, empyema requiring treatment, new central neurologic events, and other neurologic events were categories for which data were collected but no events occurred.

beyond standard monopolar cautery, and only rarely used staple line sealants.

Considering the increasing pressures to provide costeffective health care, identifying the drivers of costs for commonly performed surgical procedures - such as this analysis comparing different approaches to VATSL and

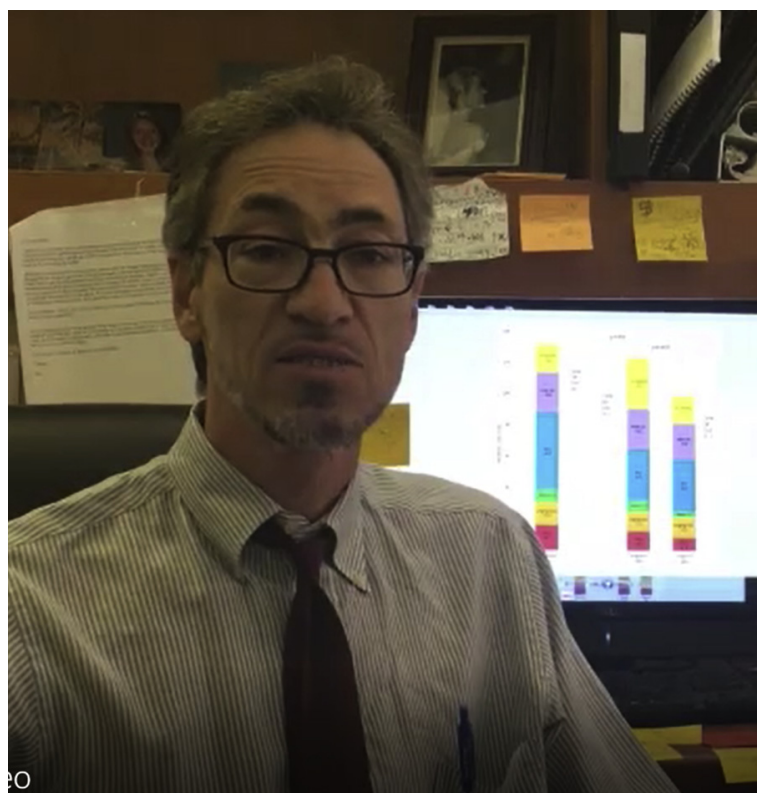

VIDEO 1. The senior author discussing the implications of the study. Video available at: http://www.jtcvsonline.org/article/S0022-5223(17) 32486-8/fulltext. comparing VATSL to THORL-will become increasingly important. Because previous studies have established that compared with THORL, VATSL (at least in stage I disease) has equivalent oncologic ${ }^{4,7,18-20}$ and quality of life outcomes, ${ }^{21}$ and reduced morbidity, ${ }^{1-3,6-10}$ it will be important to reduce the costs of VATSL to as low as safely possible. We hope that this study will focus thoracic surgeons' attention on the expensive intraoperative devices/ adjuncts that can be dispensed of without compromising patient outcomes.

Of course, a fine balance must be struck between operating with a mindset of cost-effectiveness and allowing for innovation and the potentially improved patient care that might ultimately be achieved by the pioneering of new, sometimes costly devices. Although costs should be considered, surgeon B might have been able to drive down his costs still further by using techniques that might have led to worse outcomes. As an example, ligating all pulmonary artery branches during VATSL rather than using staplers for this purpose certainly would cost less, but might lead to more bleeding catastrophes. Furthermore, there certainly will be devices that at first will have no definitively proven patient benefits and be costly, but will prove to have significant benefits over time. Would we even be capable of performing VATSL today had we not adopted stapler technology for open procedures, which at the time of introduction might have been viewed as not cost-effective? Clearly, some newer devices/supplies can be used in a cost-neutral fashion (eg, energy devices if used in lieu of staplers on small arterial branches and thin fissural tissue), whereas others (sealants, 
perhaps) may be only costly shortcuts that do not improve outcomes. Our intention is not to discourage the use or development of new devices, but only to suggest that surgeons should consider cost when determining whether to use supplies that may have no clear or proven benefit.

Our study is limited by the biases inherent in any retrospective study design. In addition, we evaluated only 2 surgeons in a single institution, and our findings might not be generalizable to a broader sample of thoracic surgeons. Similar studies at other institutions are needed to provide confirmation, although larger studies including multiple institutions are unlikely to be achievable, given the nature of the data being studied and hospitals' general reluctance to release these types of data widely. Finally, the fact that our hospital was willing to provide us with comparative but not numerical cost data was not ideal; however, the large differences in relative costs identified between the surgeons and the large statistical differences identified by even our limited statistical analyses on this dataset mitigate that issue.

In conclusion, this study provides evidence that costconscious decision making regarding the use of energy devices, staple line sealants, and disposables can safely and dramatically reduce the intraoperative costs of VATSL. We show that the intraoperative cost reductions achieved in this way can be so great as to bring the overall costs of care for VATSL down to far below those of THORL. Surgeons can, and should, educate themselves on the relative costs and demonstrated outcomes associated with the instruments and supplies that are available for use, which will allow them to choose instruments/devices more selectively and thereby improve the value of surgery. Our study provides an actionable framework that thoracic surgeons can use to safely reduce the costs of VATSL.

\section{Webcast}

You can watch a Webcast of this AATS meeting presentation by going to: https://aats.blob.core.windows.net/media/ 17AM/2017-05-02/RM302-304/05-02-17_Room302-304_ 1436_Richardson.mp4.

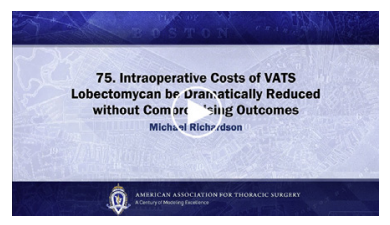

\section{Conflict of Interest Statement}

Authors have nothing to disclose with regard to commercial support.

\section{References}

1. Villamizar NR, Darrabie MD, Burfeind WR, Petersen RP, Onaitis MW, Toloza E, et al. Thoracoscopic lobectomy is associated with lower morbidity compared with thoracotomy. J Thorac Cardiovasc Surg. 2009; 138:419-25.

2. Flores RM, Park BJ, Dycoco J, Aronova A, Hirth Y, Rizk NP, et al. Lobectomy by video-assisted thoracic surgery (VATS) versus thoracotomy for lung cancer. $J$ Thorac Cardiovasc Surg. 2009;138:11-8.

3. Paul S, Altorki NK, Sheng S, Lee PC, Harpole DH, Onaitis MW, et al. Thoracoscopic lobectomy is associated with lower morbidity than open lobectomy: a propensity-matched analysis from the STS database. J Thorac Cardiovasc Surg. 2010;139:366-78.

4. Farjah F, Wood DE, Mulligan MS, Krishnadasan B, Heagerty PJ, Symons RG, et al. Safety and efficacy of video-assisted versus conventional lung resection for lung cancer. J Thorac Cardiovasc Surg. 2009; $137: 1415-21$

5. Yang CF, Sun Z, Speicher PJ, Saud SM, Gulack BC, Hartwig MG, et al. Use and outcomes of minimally invasive lobectomy for stage I non-small cell lung cancer in the National Cancer Data Base. Ann Thorac Surg. 2016;101:1037-42.

6. Park HS, Detterbeck FC, Boffa DJ, Kim AW. Impact of hospital volume of thoracoscopic lobectomy on primary lung cancer outcomes. Ann Thorac Surg. 2012; 93:372-9.

7. Whitson BA, Andrade RS, Boettcher A, Bardales R, Kratzke RA, Dahlberg PS, et al. Video-assisted thoracoscopic surgery is more favorable than thoracotomy for resection of clinical stage I non-small cell lung cancer. Ann Thorac Surg. 2007;83:1965-70.

8. Berry MF, Villamizar-Ortiz NR, Tong BC, Burfeind WR Jr, Harpole DH, D'Amico TA, et al. Pulmonary function tests do not predict pulmonary complications after thoracoscopic lobectomy. Ann Thorac Surg. 2010;89: 1044-52.

9. Kirby TJ, Mack MJ, Landreneau RJ, Rice TW. Lobectomy-video-assisted thoracic surgery versus muscle-sparing thoracotomy. A randomized trial. J Thorac Cardiovasc Surg. 1995;109:997-1002.

10. Burt BM, Kosinski AS, Shrager JB, Onaitis MW, Weigel T. Thoracoscopic lobec tomy is associated with acceptable morbidity and mortality in patients with predicted postoperative forced expiratory volume in 1 second or diffusing capacity for carbon monoxide less than $40 \%$ of normal. J Thorac Cardiovasc Surg. 2014; 148:19-29.e1.

11. Watson TJ, Qiu J. The impact of thoracoscopic surgery on payment and health care utilization after lung resection. Ann Thorac Surg. 2016;101: 1271-80.

12. Farjah F, Backhus LM, Varghese TK, Mulligan MS, Cheng AM, AlfonsoCristancho R, et al. Ninety-day costs of video-assisted thoracic surgery versus open lobectomy for lung cancer. Ann Thorac Surg. 2014;98:191-6.

13. Swanson SJ, Meyers BF, Gunnarsson CL, Moore M, Howington JA, Maddaus MA, et al. Video-assisted thoracoscopic lobectomy is less costly and morbid than open lobectomy: a retrospective multi-institutional database analysis. Ann Thorac Surg. 2012;93:1027-32.

14. Piwkowski C, Gabryel P, Galecki B, Roszak M, Dyszkiewicz W. High costs as a slow down factor of thoracoscopic lobectomy development in Poland-an institutional experience. Wideochir Inne Tech Maloinwazyjne. 2013;8:334-41

15. Rodgers-Fischl PM, Martin JT, Saha SP. Video-assisted thoracoscopic versus open lobectomy: costs and outcomes. South Med J. 2017;110:229-33.

16. Khullar OV, Fernandez FG, Perez S, Knechtle W, Pickens A, Sancheti MS, et al. Time is money: hospital costs associated with video-assisted thoracoscopic surgery lobectomies. Ann Thorac Surg. 2016;102:940-7.

17. Casali G, Walker WS. Video-assisted thoracic surgery lobectomy: can we afford it? Eur J Cardiothorac Surg. 2009;35:423-8.

18. Taioli E, Lee DS, Lesser M, Flores R. Long-term survival in video-assisted thoracoscopic lobectomy vs open lobectomy in lung-cancer patients: a meta-analysis. Eur J Cardiothorac Surg. 2013;44:591-7.

19. Berry MF, D'Amico TA, Onaitis MW, Kelsey CR. Thoracoscopic approach to lobectomy for lung cancer does not compromise oncologic efficacy. Ann Thorac Surg. 2014;98:197-202.

20. Flores RM, Ihekweazu UN, Rizk N, Dycoco J, Bains MS, Downey RJ, et al. Patterns of recurrence and incidence of second primary tumors after lobectomy by means of video-assisted thoracoscopic surgery (VATS) versus thoracotomy for lung cancer. J Thorac Cardiovasc Surg. 2011; 141:59-64.

21. Burfeind WR Jr, Jaik NP, Villamizar N, Toloza EM, Harpole DH Jr, D'Amico TA. A cost-minimisation analysis of lobectomy: thoracoscopic versus posterolateral thoracotomy. Eur J Cardiothorac Surg. 2010;37:827-32. 
Key Words: VATSL, pulmonary resection, lobectomy, lung cancer, cost-effectiveness, choice of instrumentation, costconscious, wedge resection, reduce cost, mesh, cost savings, instrumentation, cost and cost analysis, lung neoplasms, thoracic surgery, thoracic surgery, video-assisted thoracotomy

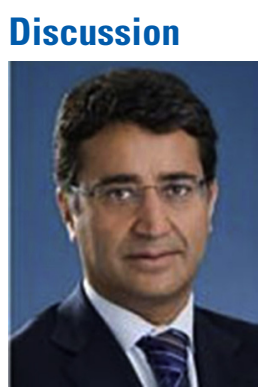

Dr S. Keshavjee (Toronto, Canada). Michael, I would like to congratulate you on an excellent piece of work, again, and on your presentation, and particularly to your teacher standing on your left, who has prepared you so well and taught you so well to make a presentation. The idea of surgeons controlling the costs of an operation by making wise choices seems intuitive and not many people have really focused on it. It is going to become increasingly important, and I think that this underscores the importance of your study in moving the field forward in bringing this concept and showing people how to measure what they do. The primary finding was that a surgeon can influence the cost without negatively influencing outcomes.

The first question I have for you is, you compared the costs of VATS lobectomies for both surgeons against each other, but when you compared it to open thoracotomy, you didn't split the two surgeons out that way. So in the open thoracotomy, was the more economical surgeon able to do even that operation at lower cost?

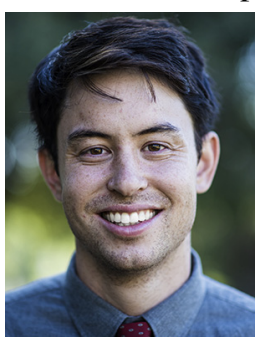

Mr Richardson (Palo Alto, Calif). They were very similar costs, and we combined them because we wanted to have a higher $\mathrm{N}$ number for open thoracotomy.

Dr Keshavjee. I think that is an important point, because it is possible that there still are learnings that way in every operation. We do not just the ones with the expensive staplers and ports.

The other question, and maybe Joe will help you on this one, is the fact that the primary driver was the cost of the staplers. Was that cost related to the type of stapler or the number of firing cartridges, and if it was that, are there any tips that the more economical surgeon, not implying that it is the one standing on the stage, might be able to give us in terms of how you can use less firings to get the job done?

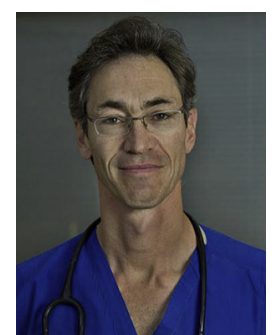

Dr J. Shrager (Stanford, Calif). Unfortunately, we couldn't figure out a way to collect the data on number of staple firings. I can just tell you my gut feeling. One of the things that accounted for the difference in staple costs is that the low-cost surgeon transitioned later to Tri-Staple, knowing that the older staplers were cheaper and thinking that they were fine. Eventually Tri-Staple just sort of took over the hospital, and I think they might have stopped making the old ones, to tell you the truth, but these days we are all using the Tri-Staple.

There are some tricks I think you can use as well-there are some obvious things. For example, you don't have to staple thin areas, you can just cauterize areas where there is no parenchyma actually crossing, which is pretty obvious to anybody with some experience.

Dr Keshavjee. And don't count on a glue that doesn't work.

Dr Shrager. Well, in terms of just the staplers, though, we can get to the glues subsequently, but for just the staplers, for the younger surgeons, when you get toward the end of the fissure and you are not sure a stapler is going to make it to the end of the parenchyma or not, you can take a right angle and sort of force it in there and push the tissue back into the stapler as you fire, and that little move will often save you a $\$ 130$ staple load. I'm looking at Dr D'Amico, who doesn't need to hear any of this stuff. Let's see, what other tricks do we have?

In Europe-I don't believe it is available here and I don't know what the economics of it would end up being - but in Europe, there is this product called TachoSil that has been very well studied, which probably does as good a job as staplers, even on fissures that have parenchyma across them where you cauterize and then you put TachoSil on. But we haven't used that.

Dr Keshavjee. Yes, I have seen that product in Japan, too, and I was very impressed.

My last comment and question is, we all work in teams and try and learn from each other and so on, so over time how would a more economical surgeon influence his colleagues in his own division and around the world to adopt the same type of behavior to control costs, and have you been able to do that?

Dr Shrager. The first thing is obviously to study it. We maybe had a sense that this was true, but we didn't really know it was true, that there was this big a difference between surgeons in their intraoperative costs. I always encourage my junior guys, for example, not to use glues, but I don't want to be controlling every little thing that they do; different people are trained different ways and have a different level of comfort with things. 
You don't want to be manipulating everything that your junior guys are doing. But I encourage them not to do it. I think when you have hard data like this, then it becomes easier to influence the way people should be doing things. It's important to be data-driven in the devices, etc. that you use.

Dr Keshavjee. Just one final comment. With regard to the energy devices and LigaSure, we know that this adds about $\$ 400$ to every case, and we don't know yet that it is better, but if you are going to encourage innovation, where do you draw the line between the fact that it is good to have people in your group innovating and looking at new ways to do it even though up front we are paying a bit more as we move along, and I think it is a cost we have to bear.

Again, congratulations. Very well done.

Dr Shrager. Thanks, Shaf. That is a very important point. You don't want to squelch innovation. Some of these things may turn out to end up being better. They might be better and more costly, which might be a worthwhile tradeoff in some cases. And I think I see Swanson in the corner of my eye over there. Maybe I will preempt him.

If we can show that one of the energy devices will work on both staple lines and all vessels less than $7 \mathrm{~mm}$, then maybe that will become more cost effective than using staplers. I'd bet that's what you're going to say.

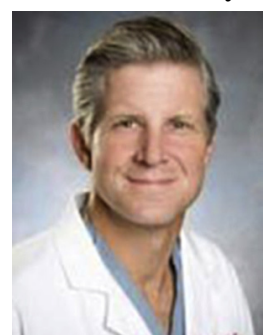

Dr S. Swanson (Boston, Mass). Well, that was one point. I think we can certainly start to do the calculus; how many staple firings is it worth to open something new, like an energy device or whatever, TachoSil is available, when do you use that, and how much does it cost. So we can start to really do this very clearly. It's a math experiment.

One point I was just going to make, and I agree with what you are doing, and even your conclusions, but I think before you can say it is cheaper without any detriment in outcome, you have got to have cancer survival, and you probably ought to have lymph node data. I am sure it is going to turn out to be similar, but without that, you can't really make that conclusion, I don't think.

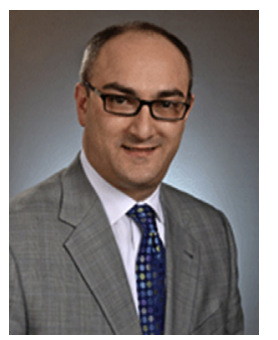

Dr M. Ebright (New York, NY). Michael, congratulations on a wonderful presentation. It is very timely and very relevant these days, as we all know.

I think what we are talking about here is specifically regarding thoracic surgery, but obviously this is generalizable to any type of surgical procedure. For those of us who serve on value analysis committees, it is something that we struggle with often.

And the point that you brought up that I think we really need to delve into or we can get the most rubber hitting the road is how do we increase the awareness of the less cost-cognizant surgeon to become more cost conscious without altering the outcome but just to have the awareness of how much things cost. What we found is that most surgeons have no idea how much things cost.

For instance, many of us who started doing robotics, when you first start your experience, you open up a suction irrigator, and you realize by the time you do it a little bit that the suction irrigator is often still sterile at the end of the case, so you get rid of the suction irrigator. So it is constant iterations as you develop experience with the procedure.

A couple of points. There are a few techniques to make that less cost-conscious surgeon more cost conscious. I wonder if you have any thoughts about it. One possibility is to actually label certain instruments as far as how much they cost, almost like you are taking it off a shelf; oh, the suction irrigator costs $\$ 600$ ? Gee, I didn't even know that, right?

Dr Shrager. That's a great idea.

Dr Ebright. So that's one way to do it. Another way to do it is to take multiple surgeons in your division who are all doing the same type of case that is reproducible and actually putting them up on a chart and starting a little bit of a competition, that, gee, this one guy is doing it for half the cost as me, what's going on, and I want to be more like him.

And then the third option, which we have not done but is brought up by the orthopedic surgeons, who use many very expensive devices and disposables and implantables, is to actually engage in cost sharing. So those surgeons who spend much less money doing the same operation, maybe that comes into their paycheck somehow as a certain percentage, and then they actually have skin in the game as opposed to just the hospital having skin in the game.

But I am wondering about your thoughts. Thank you.

Dr Shrager. Those are all very interesting ideas. Again, just going back, I don't think you can stipulate everything that surgeons do. It depends on how they were trained, their comfort level, level of experience with things. So I don't think you want to get to the point of influencing their income based on how they use this stuff.

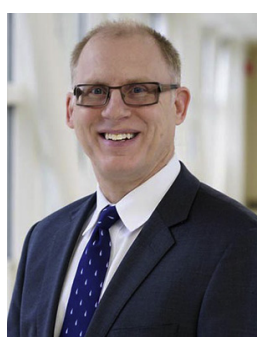

Dr T. Demmy (Buffalo, NY). One point that I would like to emphasize is the concept of a VATS reliability rate, meaning these data can only be interpreted if you know the proportion of VATS lobectomies of these surgeons' total practice. For instance, at $80 \%$ VATS of the practice, surgeons are going to be taking on central tumors, hence, they need more energy devices for hemostasis. And lung sealants if they are going to be doing patients with bad lungs versus 
surgeons operating at a smaller VATS percentage. If I look at the VATS numbers here, 100 cases over 5 years, assuming a program doing about 100 lobes a year, then the reliability rate would be only about $20 \%$ for those surgeons as far as their total practice. It is difficult to compare outcomes of VATS without knowing what case selection there is for central tumors. At higher reliability, variability improves.

Can you give us any insight as to what the proportions are?

Dr Shrager. As you saw by the numbers, I think 170 out of 270 of the lobectomies by these 2 surgeons was done by VATS. So that's probably a little more than average across the country.

I personally still like to do thoracotomies for N1 and N2 disease; that's a large part of that, but almost all of the stage I cases $(95 \%)$ were done by VATS.

I agree with most of what you said. But I don't understand why if you have a central tumor you would need Progel more. There is a little bit of data that sealants might be useful in patients who have bad $\mathrm{FEV}_{1} \mathrm{~s}$, but we didn't break down for you what the percentages of patients with bad pulmonary function were. But I can tell you that a lot of these patients do have bad pulmonary function. That is not a reason for us not to do a VATS case. Those would be purely cancer reasons.

Unidentifed speaker. Correct me if I am wrong, but the cost-effective surgeon took longer in the OR?

Mr Richardson. No, the other way around. 
TABLE E1. VATSL and open patient demographics and preoperative risk factors

\begin{tabular}{|c|c|c|c|}
\hline Variable & All VATSL & Open & $P$ value \\
\hline Number of patients & 169 & 100 & \\
\hline Age, $y$, mean $(\mathrm{SD})$ & $65.43(12.87)$ & $61.39(14.12)$ & $.02 *$ \\
\hline Female sex, $\mathrm{n}(\%)$ & $108(64 \%)$ & $46(46 \%)$ & $<.01 \dagger$ \\
\hline$\%$ of predicted $\mathrm{FEV}_{1}$, mean $(\mathrm{SD})$ & $92.39(22.77)$ & $88.47(27.04)$ & .23 \\
\hline Major comorbidities, $\mathrm{n}(\%)$ & $77(46 \%)$ & $33(33 \%)$ & $.05^{*}$ \\
\hline Peripheral vascular disease, $\mathrm{n}(\%)$ & $2(1 \%)$ & $4(4 \%)$ & .20 \\
\hline Cerebrovascular history, $\mathrm{n}(\%)$ & $4(2 \%)$ & $0(0 \%)$ & .30 \\
\hline Congestive heart failure, $\mathrm{n}(\%)$ & $6(4 \%)$ & $1(1 \%)$ & .26 \\
\hline Chronic obstructive pulmonary disease, $\mathrm{n}(\%)$ & $29(17 \%)$ & $17(17 \%)$ & 1.0 \\
\hline Coronary artery disease, $\mathrm{n}(\%)$ & $13(8 \%)$ & $9(9 \%)$ & .82 \\
\hline Diabetes, n (\%) & $22(13 \%)$ & $10(10 \%)$ & .56 \\
\hline Creatinine $\geq 1.2 \mathrm{mg} / \mathrm{dL}, \mathrm{n}(\%)$ & $33(20 \%)$ & $18(18 \%)$ & .87 \\
\hline
\end{tabular}

VATSL, Video-assisted thoracoscopic lobectomy; $S D$, standard deviation; $F E V_{l}$, forced expiratory volume in 1 second. $* P \leq .05$. $\dagger P \leq .01$

TABLE E2. VATSL versus open tumor characteristics and procedures performed

\begin{tabular}{|c|c|c|c|}
\hline Variable & $\begin{array}{c}\text { All VATSL, } \\
\text { n (\%) }\end{array}$ & $\begin{array}{l}\text { Open, } \\
\text { n (\%) }\end{array}$ & $\begin{array}{c}P \text { value for } \\
\text { category }\end{array}$ \\
\hline Number of patients & $169(100)$ & $100(100)$ & \\
\hline Disease category & & & .45 \\
\hline Primary: upper lobe & $72(43)$ & $43(43)$ & \\
\hline Primary: middle lobe & $9(5)$ & $3(3)$ & \\
\hline Primary: lower lobe & $54(32)$ & $33(33)$ & \\
\hline Metastasis & $21(12)$ & $8(8)$ & \\
\hline Other & $13(8)$ & $13(13)$ & \\
\hline Tumor stage* & & & $<.01 \dagger$ \\
\hline IA & $93(55)$ & $24(21)$ & \\
\hline IB & $24(14)$ & $14(14)$ & \\
\hline IIA & $8(5)$ & $8(8)$ & \\
\hline IIB & $5(3)$ & $0(0)$ & \\
\hline IIIA & $5(3)$ & $13(13)$ & \\
\hline IIB & $0(0)$ & $2(2)$ & \\
\hline IV & $0(0)$ & $16(16)$ & \\
\hline Lobe involvement & & & .31 \\
\hline Upper lobe & $83(49)$ & $55(55)$ & \\
\hline Middle lobe & $12(7)$ & $3(3)$ & \\
\hline Lower lobe & $74(44)$ & $42(42)$ & \\
\hline Type of procedure & & & $<.01 \dagger$ \\
\hline Lobectomy & $140(83)$ & $97(97)$ & \\
\hline Segmentectomy & $29(17)$ & $3(3)$ & \\
\hline
\end{tabular}

